\title{
EL ROSTRO DEL PADRE EN SAN JUAN
}

Santiago Andrade, ofm. ${ }^{1}$

\section{A. INTRODUCCIÓN}

El año dedicado al Padre es una invitación urgente a conocer su rostro paterno y materno así como lo ha revelado Jesús de Nazaret. Pero, no sólo a conocerlo, sino a experimentarlo gozosamente para darlo a conocer a los demás, en obras y palabras. Un año dedicado a Dios Padre nos brinda sin duda una excelente oportunidad para evangelizar sobre un aspecto fundamental de nuestra fe, desconocido por muchos y olvidado con frecuencia: que Dios es Padre, y en lo más íntimo del corazón del Padre, se encuentra su misericordia. Muchos cristianos viven aún temerosos de un Dios arbitrario que pareciera ser autor de las desgracias que nos visitan en la vida. A otros, les parece que Dios, si existe, es indiferente a la suerte de la humanidad. Y más de alguno tiene todavia la imagen de un Dios justiciero, castigador y vengativo.

El Dios de Jesús no es así, sino que se nos presenta con un rostro amable misericordioso. Por eso es importante, antes de cualquier reflexión acerca de Dios Padre, recurrir a la fuente principal de nuestra vida: Ia Biblia, y descubrir alli, sobre todo en el Nuevo Testamento, el rostro de Dios Padre que nos presenta Jesús de Nazaret. El punto de partida para hablar de la paternidad de Dios no está en la relación humana entre padre e hijos, sino en la relación de Jesús con su Padre. Por eso es tan importante meditar la vida de Jesús, su actitudes ante Dios-Padre, sus palabras dirigidas al Padre, su anuncio del Reino de Dios, los milagros y signos que hace, para conocer de verdad al Padre.

Frente a esto cabe señalar que si llamamos a Dios Padre es porque primero es Padre de Jesús, y que él nos ha mostrado el rostro del Padre. Nunca se destacará suficientemente que nuestra actitud filial que ve en Dios a un Padre, está estructuralmente vinculada a (y dependiente de) nuestra adhesión a Jesús. Por tanto, nuestra experiencia del Padre va a depender de la experiencia y del conocimiento que tengamos de Jesucristo. El concepto de "Padre» que tenemos cuando nos dirigimos a Dios, no lo hemos heredado de ninguna fuente, ni siquiera

\footnotetext{
$1 \quad$ Ponencia presentada en el V Coloquio de Teologia "Dios como Padre. Perspectivas para la evangelización", organizado por el Instituto de Estudios Teológicos de la Universidad Católica de Temuco, en octubre de 1999.
} 
del Antiguo Testamento, sino de la vivencia que tenía de Dios Padre el Señor Jesús. Si somos hijos de Dios lo somos en el Hijo de Dios (Jesucristo), de allí que es importante descubrir cómo el «Dios de Jesucristo» (Ef 1,17; Jn 21,17) era para Él, «Padre», qué alcance concreto tenia para Él su paternidad.

Hoy día se está de acuerdo que la expresión usada por Jesús para llamar a Dios, "Padre" fue Abbá, palabra aramea de uso muy corriente en el lenguaje coloquial, como nuestra palabra «papá», que no se encuentra jamás referido a Dios en la literatura judía, por expresar mucha intimidad, lo cual es visto como una ofensa a Dios. Jesús lo usó para dirigirse a Dios según lo atestiguan algunos textos, como Mc 14,36; Gál 4,6 y Rom 8,15. Esto demuestra que nuestro Dios es alguien con quien se puede tener una relación de cercanía intima y afectiva. Y aún más, los estudiosos están de acuerdo en señalar, que en todos los textos evangélicos en que encontramos a Jesús dirigiéndose a Dios como Padre, aunque por la lengua griega se use la expresión Patér, está subyacente el arameo Abbá (cfr Lc10,21 y par; 11,2; 13,30 y muchos más). Aún más, todos los textos del Nuevo Testamento que nos hablan de «Dios» se refieren al Padre, aunque no se encuentre la palabra «Padre».

El tema del Padre lo vamos a reflexionar según la presentación que nos hace el Cuarto evangelio ${ }^{2}$, porque precisamente este evangello es el que asume como su tarea especifica la de desarrollar ampliamente y en forma profunda la relación que existe entre Jesús de Nazareth y su «Padre» (cfr Jn 8,31-59; 17,1-8). Esta relación es de extraordinaria cercanía, intimidad y confianza. Jesús nos ha comunicado que su «Abbá» es como un Padre atento y solicito preocupado siempre de lo que pueda ocurrirle a sus hijos; el Padre es alguien que garantiza con su perdón, una nueva aurora y da la posibilidad de volver a comenzar (cfr Jn 8,1-11). Confiar en un Dios Padre así, llevó a Jesús a mantenerse fiel, a esperar en su promesa a pesar de la contradicción, la persecución, la condena, la muerte en cruz. La confianza sin límites en su Padre bondadoso es la raíz de donde brota la entrega, también sin límites, a su voluntad. porque poco se habla y se escribe; lo mismo habría que decir del Padre, que no siempre ha corrido buena suerte. Si damos un vistazo a los grandes comentarios biblicos de Juan, como SCHNACKENBURG, DODD, BARRET, BROWN por nombrar algunos, no tocan para nada el tema del Padre. E. MALATESTA, que se ha dedicado a recopilar todos los estudios que se han hecho sobre san Juan desde 1920 hasta 1965 , hace referencia a 9 títulos referidos al Padre. A. Moda, que continúa el mismo trabajo hasta 1972, no menciona ninguno. Sólo dos ensayos afrontan el tema de un modo explícito. El primero es el de C.K. BARRETT, que fue presentado en la Jornada błblica de Lovaina en el año 1974, que versaba sobre el tema "La notion biblique de Dieu», publi-. cado en 1976:" Christocentric or Theocentric? Observations on the Theological Method of the Fourth Gospelı. El segundo es el de G. SEGALLA, /I Dio inaccessibile di Giovanni, A. B. L.., Torino, 1980. Actualmente, gracias a Dios han salido algunos artículos que mencionaremos más adelante. 


\section{B. El Padre en el Cuarto Evangelio}

El relato evangélico que la tradición atribuye al apóstol Juan es una obra muy diferente la de los otros evangelistas ${ }^{3}$. Sus diferencias son notables en varios aspectos: estilo, vocabulario, cronología, personajes, etc. Respecto a nuestro interés más concreto, Dios Padre, cabe destacar, en primer lugar, una divergencia claramente apreciable: el número de referencias. Mientras en los tres sinópticos (Mateo, Marcos y Lucas) suman, en conjunto, una cincuentena de alusiones directas, el evangelio de Juan llega, él solo, al centenar $r^{4}$. La desproporción es, cuanto menos, llamativa, y se dará también en la relación entre las cartas joánicas y el resto de las epistolas del Nuevo Testamento.

Para poder navegar por este extenso mar sin perdernos demasiado, utilizaremos como elemento unificador, ajeno, eso sí, al desarrollo del propio evangelio, pero en consonancia con el modo con que su autor (o mejor, autores) tiene de ir abordando los temas. Se trata de los distintos diálogos que constituyen el soporte literario de los discursos de Jesús. En trasfondo de estos diálogos, y a veces también en un primer plano, el rostro invisible del Padre Dios se hace perceptible en todas y cada una de las palabras de su Hijo. Los personajes que intervienen en estos diálogos y las relaciones que establecen con Jesús pueden ser unas buenas torres desde donde mirar ese rostro paternal y divino que el propio Jesús revela con su palabra y con su vida.

Para no dispersar la atención en la multitud de participantes que aparecen en estos diálogos, concentraremos la mirada en grupos claramente diferenciados: el primero, formado por un solo integrante, el propio Padre de Jesús; el segundo, constituido por un grupo más amplio y que, poco a poco, se va reduciendo, el de sus discípulos; y el tercero y último, compuesto por un número indeterminado cuya característica común es la franca oposición a Jesús en todo momento, el de sus adversarios. Comencemos con las relaciones entre Jesús y su Padre tal y como se recogen en el Cuarto Evangelio.

\section{Relaciones entre Jesús y su Padre}

En el Cuarto Evangelio, el vínculo de Jesús con su Padre es tan fuerte que difícilmente podrían establecer diferencias; con la salvedad de aquellas que se desprenden, como natural, de la doble condición de Jesucristo, como ser humano y R. SCHNACKENBURG, El evangelio según san Juan, vol. I. Herder, Barcelona 1980, pp. 43-217.

Cfr M. GUERRA CAMPOS, El idioma del Nuevo Testamento, Burgos, Aldecoa, 1981, pp. 151241 contiene la estadistica publicada anteriormente por R. MORGENTHALER, publicada en Zurich el año 1958, donde señala que la palabra «Padre» aparece 137 veces en Juan. Se incluye aquí las palabras que se refieren a los antepasados o de per sonas que no tienen mucho que ver con Dios. Según la misma fuente, "Padre» está usado 415 veces en todo el Nuevo Testamento. J. JEREMíAS, Abbá y el mensaje central del Nuevo Testamento, Salamanca 1983, pp. 37-61, la reduce a 109 veces. 
como enviado de Dios ${ }^{5}$. El Padre aparece como el centro unificador y totalizador de la existencia de su Hijo, su voluntad rige todos los movimientos de su enviado; de modo que el obrar de Jesús se corresponde con el de su Padre, e igualmente sus palabras. Por esta razón: quien ve a Jesús ve igualmente al Padre; todo lo que el Padre tiene es del Hijo, y viceversa; el Hijo es glorificado en el Padre, el Padre en el Hijo. Y así sucede con todo lo que va surgiendo en el desarrollo del relato evangélico. Incluso, hasta el juicio lo ha dejado el Padre en manos del Hijo $(5,22 ; \mathrm{cfr} 8,16)$.

Ya desde el principio, desde el texto conocido como prólogo (Jn 1,1-18) ${ }^{6}$, el cuarto evangelio muestra a Jesús como la Palabra encarnada de Dios. Palabra cuya existencia se remonta a un tiempo anterior incluso a la creación misma. Y ya entonces «estaba junto a Dios y era Dios». La preposición griega pros (junto a ) significa no sólo cercanía, sino también movimiento, dirección, relación; la Palabra estaba cara a cara con Dios. Por lo tanto, la Palabra no está solamente cercana al Padre, sino vuelto a él, en posición de quien escucha y recibe ${ }^{7}$ todo de él. Este dinamismo de la relación entre el Padre y el Hijo queda bien de manifiesto en el vocablo ho theós con artículo, que en Juan indica siempre la persona del Padre (cfr $3,16-17 ; 6,27 ; 8,42)$, mientras que el uso sin artículo significa la naturaleza, como se dice en el estiquio siguiente: "y la Palabra era Dios» (v. Ic $)^{8}$. Es decir, la Palabra, a pesar de ser distinto de Dios Padre, no es otra divinidad, sino que es el mismo Dios, como nos confirma también el testimonio de Tomás después de la resurrección de Jesús: «Señor mío y Dios mío» (Jn 20,28).

Por esta razón, no es extraño que en el transcurso del evangelio la identificación de Jesús con el Padre se vaya haciendo cada vez más patente hasta el punto de llegar a decir: «El Padre y yo somos uno» (Jn 10,30). Y la unidad que Jesús dice tener con su Padre es radicalmente diferente a cualquier otra. Por eso, Jesús es auténtico revelador del Padre, sólo él puede darlo a conocer de verdad: «A Dios nadie le visto jamás: el Hijo único, que es Dios, y que está en el seno del Padre, él lo ha contado" $(1,18)^{9}$. Los creyentes de todos los tiempos han deseado conocer a Dios y han tratado de abrir caminos para comunicarse con él. La voz del salmista recoge este anhelo al preguntarse "¿Cuándo entraré a ver el rostro de Dios?» (Sal $42,3)$. El prólogo del evangelio de Juan se atreve a responder con una afirmación tajante que parece frustrar toda esperanza. «A Dios nadie le ha visto jamás» $(1,18)$. Y si nadie lo ha visto, nadie sabe de verdad quién es ni puede hablarnos de él. Si

Un buen artículo sobre el Padre en Juan es el de G. SEGALLA, «Dio Padre di Gesu nel Quarto Vangelon, en Scuola Cattolica 117 (1989), 196-224.

El prólogo de san Juan ha sido muy estudiado; solamente señalo: M.E. BOISMARD, El prólogo de San Juan, Madrid 1970; A. FEUILLET, Le Prologue du quatrieme Évangile, Brujas 1968.

Cfr sobre el tema de la relación entre el Padre y el Hijo, I. DE LA POTTERIE, "L'emploi dynamique de "eis» dans saint Jean et ses incidences théologiques": en Biblica 43 (1962), pp. 379-387.

El uso de Theós (Dios) sin articulo, en Juan, sirve para distinguir a la Palabra (Jesucristo) del Padre y expresa su naturaleza: no es inferior al Padre como creen los mormones y los testigos de Jehová que traducen: «y la Palabra era un dios" (con minúscula). La Palabra es Dios, aunque distinto del Padre en cuanto persona.

Los textos bíblicos están tomado de la Biblia de Jerusalén, nueva versión revisada y aumentada, DDB, Bilbao, 1998. 
damos crédito a estas palabras, debemos aceptar que Dios prefiere vivir aislado y solitario, como alguien incapaz de salir de sí mismo para expresarse.

Pero afortunadamente, el prólogo de Juan tiene algo que añadir. Hay alguien que si que ha visto a Dios y lo conoce. Hay alguien que puede, con toda autoridad, hablarnos de él, el Hijo único que es Dios y que está en el seno del Padre, nos lo ha dado a conocer $(\mathrm{Jn} 1,18)^{10}$. Y también: «No es que alguien haya visto al Padre; sino aquel que ha venido de Dios, ése ha visto al Padre» (Jn 6,46). Esta singular unidad de Jesús con su Padre lo convierte, como hemos dicho, en el auténtico revelador; y serán sus hechos y sus palabras los que den conocer a los demás quién y cómo es el Padre. Ellos acreditan a Jesús como enviado del Padre, al tiempo que testimonian su unidad con él: "Creedme: yo estoy en el Padre y el Padre está en mí. Al menos, creedlo por las obras» (Jn 14,11).

De este modo podemos preguntarnos, ¿cómo es el Padre?: como es Jesús (cfr 14,9s); ¿Qué hace el Padre?, lo que hace Jesús; pues nada realiza por sí mismo: «En verdad, en verdad os digo: el Hijo no puede hacer nada por su cuenta, sino lo que ve hacer al Padre: lo que hace él, eso también lo hace igualmente el Hijo" (Jn $5,19 \mathrm{~s}$ ). Y es un obrar constante, para el que no existe momento de descanso. Por eso, cuando los «judios»-término con que generalmente este evangelio denomina a los adversarios religiosos de Jesús- le recriminan sus curaciones en sábado, Jesús se justifica con la propia actuación de Dios: «Mi Padre trabaja hasta ahora, y yo también trabajo» (Jn 5,17).

El particular conocimiento mutuo de Jesús y su Padre $(\mathrm{Jn} 10,15)$ hace que no se produzcan diferencias entre el decir y el hacer de uno y otro. Jesús proclama lo que el Padre le encargó: «Porque yo no he hablado por mi cuenta, sino que el Padre que me ha enviado me ha mandado lo que tengo que decir y hablar» (Jn 12,49); está tan identificado con él que su vida entera lo revela. Las obras y las palabras de Jesús dan testimonio del Padre, y al mismo tiempo, las obras del Padre dan testimonio de su enviado: "Yo tengo un testimonio mayor que el de Juan; porque las obras que el Padre me ha encomendado llevar a cabo" (Jn 5,36; cfr 8,18). Y la unidad que venimos repitiendo hasta este momento tiene un claro nexo de unión: el $a^{11}$. Por el amor que le tiene, el Padre entrega al Hijo todo lo que es suyo (Jn $3,35)$, y por ese amor le muestra todo lo que él mismo hace, para admiración de los discípulos (Jn 5,20).

Empleando una imagen de gran fuerza en la cultura de su época, Jesús compara a su Padre con un viñador, y él mismo se compara con la vid (los discípulos son los sarmientos). La vida del Hijo, de la vid, la cuida y sostiene el Padre, el viñador. La vida de Jesús tiene, de esta manera, una existencia peculiar, que no se aoristo indicativo del verbo exegéomai, que se puede traducir por: «dio a conocer», "reveló", "expuso" o "explicó». De aquí tambièn nacen dos sustantivos: "exégesis» y "exégetan. Entonces, podemos decir, que el Hijo úníco se ha convertido en exégeta del Padre. 
agota, porque viene de Dios, y de ella dispone para llevar a término la misión que le ha encargado su Padre Dios ${ }^{12}$. Y en esa disposición de su vida, y precisamente por el amor que le une a su Padre, Jesús la entrega en el mundo para recobrarla de nuevo: «Por eso me ama el Padre, porque doy mi vida, para recobrarla de nuevo. Nadie me la quita; yo la doy voluntariamente. Tengo poder para darla y poder para recobrarla de nuevo; esa es la orden que he recibido de mi Padre» (Jn 10,17-1). Así pues, si el comienzo del evangelio nos remitía a los orígenes del Hijo, de la Palabra, en el Padre, su posterior desarrollo hace retornar su existencia nuevamente a su fuente: «Salf del Padre y he venido al mundo; ahora dejo otra vez el mundo y voy al Padre" (Jn 16,28; cfr 13,3). El regreso de Jesús junto a su Padre significa, pues, su glorificación. Pero esta marcha no está exenta de dolor, ya que va a ser violenta. Podría eludirla, pero eso supondría trastocar los designios del Padre, y él ha venido precisamente a realizarlos (cfr Jn 18,11).

El rostro del Padre en el momento crucial en que su Hijo le entrega su vida es el del Señor de la vida. De él procede y a él retorna toda existencia. Y, a través de Jesús, sus seguidores alcanzarán la vida eterna. Amante de los contrastes, el cuarto evangelio nos ofrece, en ese tenso antagonismo de la vida y la muerte, de la cruz y la gloria, el triunfo del plan salvador de Dios Padre.

\section{Jesús, el Padre y los discipulos}

La vida es el gran don que el Padre otorga a todas las personas por medio de su Hijo, único camino por el que se puede llegar hasta él. En el contexto de la identificación de ambas personas a la que antes aludiamos, el evangelio plantea ahora para los discípulos un camino de doble sentido: del Hijo hacia el Padre y del Padre hacia el Hijo. Jesús es el camino para ir al Padre, para acceder a la verdad y a la vida $(\mathrm{Jn} 14,6)^{13}$. Pero, al mismo tiempo, dirá también Jesús: «Nadie puede venir a mí si no se lo concede el Padre» (Jn 6,65). De donde se desprende, una vez más, la estrecha relación entre ambos; en esta ocasión, referida al encuentro de los discípulos con Jesús y con su Padre. En diversas ocasiones insistirá Jesús en esa acción directa del Padre, guiando hacia su Hijo a los discípulos. Y siempre con consecuencias vitales para ellos:

a) La fidelidad del Padre con los hijos sostiene la fidelidad de Jesús, conforme a la voluntad del que lo envió. El Hijo no ha venido a realizar un proyecFERRANDO, "Dios Padre en el evangelio según san Juan", Anales de la Facultad de Teologia, cuaderno1, voi. XLVII, Santiago de Chile 1996. Ya antes, el mismo autor nos habia presentado un anticipo con motivo del homenaje que la Facultad rindió a dos de sus profesores: Antonio Moreno y Beltrán Villegas, cuyo título es "Apuntes para una teologia del Padre en el Evangelio según San Juan", Anales de la Facultad de Teología, vol.XXXIX (1988). 
to personal, sino que encomendado por su Padre; por eso, aquel que su Padre le entrega, él no lo rechazará (Jn 6,37s).

b) Jesús es la vida. El fruto de la fidelidad del Hijo a sus seguidores es, por voluntad del Padre, la resurrección en el día final $(\mathrm{Jn} 6,44)$.

c) Jesús es también, el «pastor» de sus seguidores, que están siempre seguros, porque el Padre, que es poderoso, no permitirá que ninguno de ellos sea arrebatado de las manos del pastor (Jn 10,29) ${ }^{14}$.

El rostro de Dios que ha quedado bien patente en estos textos es el de un Padre absolutamente fiel a sus hijos, a los que, por medio de su Unigénito, les ofrece la verdadera Vida, la resurrección: «Porque esta es la voluntad de mi Padre: que todo el que vea al $\mathrm{Hijo}$ crea en él, tenga vida eterna y que yo le resucite el último día» (Jn 6,40;cfr 5,21). Esta Vida que procede del Padre se le comunica al discípulo por la intima comunión con el Hijo. Comunión que alcanza el nivel máximo de expresión y de vivencia en el sacramento de eucaristia, como se desprende de 6,5157. Y la Vida que el Padre ofrece a sus hijos por medio de su Unigénito está penetrada por el mismo amor que les une a ellos dos. De modo que escuchar y cumplir la voluntad del Padre implica previamente acoger la palabra del Hijo es aceptar sus enseñanzas y cumplir sus mandamientos, que son, en última instancia, los del Padre.

Cuando el discipulo asume en su vida esa triple relación, entabla una profunda e íntima comunión con el Padre y el Hijo: «Si alguno me ama, guardará mi palabra, y mi Padre lo amará, y vendremos a él, y haremos morada en él" (Jn 14,23). Por eso, se invita al discípulo mantener con fidelidad ese vínculo de amor que les une a los tres: «Como el Padre me ama yo también os he amado a vosotros; permaneced en mi amor» (Jn 15,9 $)^{15}$. Pero no se trata de un amor abstracto, o puramente sentimental. El amor a Jesús se concreta y expresa en el cumplimiento de sus mandamientos. La observancia manifiesta el amor verdadero del discipulo y fortalece su relación con el Hijo, y, a través de él, con el Padre: «El que tiene mis mandamientos y los guarda, ése es el que me ama; y el que me ame, será amado de mi Padre; y yo le amaré y me manifestaré a él" (Jn 14,21). Y del mismo modo: "Si guardáis mis mandamientos, permaneceréis en mi amor, como yo he guardado los mandamientos de mi Padre, y permanezco en su amor» (Jn 15,10). Así, el Padre se revela como quien, por medio de la enseñanza de Jesús, de sus preceptos, instruye y orienta la vida de sus hijos.

Es posible que estos términos que el Cuarto evangelio emplea de obedecer, observar los mandamientos, puedan conducir a equivocos al lector moderno. Si se comprenden fuera de su contexto parecería que Dios Padre fuera un dictador para sus hijos, los cuales debería comportarse como sirvientes a los que se les hubiera privado de libertad y voluntad. Como se ha visto, la constante referencia al amor que hace el evangelista es la clave para comprende la auténtica obediencia que

Para un comentario amplio del Buen Pastor, cfr R. SCHNACKENBURG, El evangelio según san Juan, tomo IV, pp. 139-152; y también: S.A.PANIMOLLE, Lettura pastorale del Vangelo di Giovanni, vol.II,EDB,Bolonia, 1991, pp. 429-468. 
Jesús está proponiendo a sus discípulos. Una obediencia que debe evitar en todo momento el servilismo que muchas desviaciones religiosas han reclamado, y aún siguen reclamando, a lo largo de la historia.

El ideal del discípulo es lograr una comunión de amor intensa con Jesús, su Maestro, modo que sea el amor ${ }^{16}$, y no otras motivaciones, el que oriente toda su vida y la configure acuerdo con el proyecto que el Padre tiene para él, un proyecto de plenitud y de vida, resurrección, cuyo modelo es el propio Jesús, el Hijo, que ha sido glorificado ya por el Padre.

El mayor mandato de Jesús a sus discípulos es, precisamente, la exigencia del amor: «Os doy un mandamiento nuevo: que os améis los unos a los otros. Que, como yo os he ama así os améis también vosotros los unos a los otros. En esto conocerán todos que sois discípulos míos: si os tenéis amor los unos a los otros» (Jn 13,34-35) ${ }^{17}$. Y ese amor, que no es abstracto, como ya se ha dicho, se concreta en obras, en acciones semejantes a las de Jesús y aun mayores (Jn 14,12); en obras que son la verdadera glorificación del Padre (Jn 15,8). Así, del mismo modo que el Padre envió a su Hijo, ahora este Hijo es quien envía a los discípulos (Jn $20,21)^{18}$, a sus «amigos», para que sigan actuando en su nombre ( $\left.\operatorname{In} 15,16\right)$.

La obediencia del discípulo, su actuación conforme a la voluntad del Padre, se basa en la confianza, el respeto y la fidelidad. Por eso, Jesús llama a sus discipulos «amigos», al tiempo que rechaza la consideración de «siervos». ¿Y sobre qué se construye esa amistad? Sobre conocimiento de cuanto el Padre dice: "No os llamo ya siervos, porque el siervo no sabe que hace su amo; a vosotros os he llamado amigos, porque todo lo que he oído a mi Padre os lo he dado a conocer» (Jn 15,15). Por el conocimiento que los discípulos tienen del Padre gracias a la revelación de Jesús, pueden buscarlo en todo momento y lugar. Los templos, cualquier otro ámbito sagrado, se vuelven innecesarios, inútiles, ineficaces. Pues el Padre, que está en todas partes, puede ser encontrado y reconocido por sus hijos en cualquier lugar. Tal se deduce, entre otros casos, del encuentro de Jesús con la samaritana: «Le dice la mujer: Señor, veo que eres un profeta. Nuestros padres adoraron en este monte y vosotros decís que en Jerusalén es el lugar donde se debe adorar. Jesús le dice: Créeme, mujer, que llega la hora en que, ni en este monte, ni en Jerusalén adoraréis al Padre. Vosotros adoráis lo que no conocéis; nosotros adoramos lo que conocemos, porque la salvación viene de los judíos. Pero llega la hora (ya estamos en ella) en que los adoradores verdaderos adorarán al Padre en espíritu y en verdad, porque asi quiere el Padre que sean los que le adoren» (Jn 4,19-24).

Y si cualquier lugar es válido para encontrarse con el Padre, también lo es cualquier momento. La confianza es la base firme donde se apoya la oración. IncluBrescia 1982, pp 50-67; sobre todo su obra más antigua, "Agape dans le Nouveau Testament. Analyse des textes III", Études Bibliques, Paris, Gabalda 1959. 
so en las circunstancias más adversas. Pues el Hijo es siempre el mediador eficaz: «En verdad, verdad os digo: lo que pidáis al Padre os lo dará en mi nombre» (Jn $16,23 ; \mathrm{cfr} 14,13 ; 15,16)$. Aunque hasta esta mediación llega a hacerse innecesaria por el mismo amor del Padre: «Aquel dia pediréis en mi nombre y no os digo que yo rogaré al Padre por vosotros, pues el Padre mismo os quiere» (Jn 16,26-27a).

Por último, el amor que reiteradamente ha ido apareciendo en el centro de la triple relación entre Jesús, su Padre y los discípulos, tiene una consecuencia final: la unidad entre los hijos. Hasta ahora, los textos que han ido apareciendo incidian en la unión entre el Padre y el Hijo o, entre ambos y discípulos. Pero también esta unión ha de darse en los propios hijos. Dios no aparecería como buen Padre si el conjunto de su familia estuviera dividida. De ahí la gravedad imperiosa de la unidad. Que ciertamente no es un logro humano, sino un don como todo que procede de Dios.

Una de las imágenes del Padre que el cuarto evangelio ha grabado más profundamente en la mente de sus lectores es la de un Dios al que sus fieles reconocen como Padre al tiempo que ellos mismos viven como hermanos. El texto más ilustrativo de esto que decimos es, sin duda, el que forma parte de la llamada "oración sacerdotal» de Jesús ${ }^{19}$, elevada al Padre poco antes de morir y que, en dos momentos, dice asi: «Padre Santo, cuida en tu nombre a los que me has dado, para que sean uno como nosotros» (Jn 17,11). «No ruego sólo por éstos, sino también por aquellos que, por medio de su palabra, creerán en mí, para que todos sean uno. Como tú Padre, en mi y yo en ti, que ellos también sean uno en nosotros para que el mundo crea que tú me has enviado. Yo les he dado la gloria que tú me diste, para que sean uno como nosotros somos uno: yo en ellos y tú en mi, para que sean perfectamente uno, y el mundo conozca que tú me has enviado y que los has amado a ellos como me ha amado a mí» (Jn 17,20-23). Esta larga oración que conocemos con el nombre de "oración sacerdotal», porque en ella Jesús se sitúa como sacerdote ante el Padre para interceder por todos nosotros. Si nos fijamos en los motivos de su intercesión, podemos descubrir en el tres partes. En la primera (Jn 17,1-8) Jesús intercede por sí mismo; en la segunda $(17,9-19)$ ora por sus discípulos; y en la tercera (Jn 17,20-26) por aquellos que crean por el testimonio de ellos.

En la primera parte (Jn 17,1-8) pide al Padre que confirme su obra en el momento decisivo que se acerca "la hora»; El ha sido fiel al encargo recibido, y ha conservado a todos aquellos que el Padre le había confiado, manifestándoles la vida eterna y comunicándoles la palabras de Dios para que las guarden ${ }^{20}$. En la segunda, ora por sus discípulos más directos (Jn 17,9-19). Su situación es muy parecida a la que reflejan los capítulos precedentes (Jn 15,16): se encuentra en medio del mundo porque él mismo los envió, pero no son del mundo; Jesús ora para que en medio de sus dificultades experimenten la alegría que procede de

Para un comentario de este texto, ver: J. MATEOS - J. BARRETO, El evangelio de Juan, Cristiandad, Madrid 1982, pp. 702-732; S.A. PANIMOLLE, Lettura pastorale, Vol. III, pp. 339-370; G. ZEVINI, Evangelio según san Juan,Sigueme, Salamanca 1995, pp. 409-428. 
él, para que sean librados del mal. Finalmente, Jesús ora por todos los que creerán en él por medio de la palabra de estos primeros discipulos (Jn 17,2026). Son los discípulos de la segunda generación; han llegado a conocer que el Padre envió a Jesús, y él les ha comunicado su amor. El problema con que se enfrentan en esta nueva etapa no es ya el odio del mundo, sino la división interna, que puede dificultar su testimonio hacia el mundo. Por eso Jesús pide para ellos la unidad ${ }^{21}$.

El pasaje de Jn 17,20-23, comienza identificando a aquellos por quienes Jesús intercede, lo hace con dos pinceladas. Dice, en primer lugar, que crean en él. Esta afirmación tiene un significado preciso en el evangelio de Juan. Creer en Jesús significa reconocer que procede de Dios y estar unido a él, guardando y cumpliendo sus palabras; o dicho de otra forma reconocerle como Hijo de Dios (Jn 20,31). En segundo lugar, se dice que han llegado a la fe través del testimonio de otros. Estos discípulos son el fruto de la tarea evangelizadora que encomendó a sus primeros discípulos: «Como tú me has enviado al mundo, yo también los he enviado al mundo» (Jn 17,18). Jesús les envió para que dieran testimonio de él (Jn 19,35; 20,21) y gracias a este testimonio otros han creído en él. Jesús ora aqui por todos los que creerán en él sin haberle conocido personalmente.

Lo que Jesús pide para ellos es «que sean uno» (en eimi). Llama la atención el hecho de que esto se repita tres veces (w. 21,22 y 23). Se trata sin duda de algo muy importante. Las cartas de Juan, dirigidas probablemente a la misma comunidad que el evangelio, nos han dejado un testimonio de las divisiones que acechaban a estas comunidades cristianas de segunda generación, y puede servirnos para descubrir el significado preciso de esta petición de Jesús. En ellas se habla de divisiones doctrinales, como la provocada por aquellos que reconocían la intima relación entre Jesús y el Padre (Jn 1,18-27). En otros casos se trata divisiones causadas por el deseo de controlar a la comunidad, como en el caso de Diotrefes mencionado en la tercera carta (3Jn 9-11). No es, pues, una intención imprecisa y genérica sino que se refiere a situaciones concretas que vivían los cristianos de la segunda generación.

La unión entre los miembros de la comunidad debe seguir el modelo de la íntima unión que se da entre Jesús y el Padre: "Yo les he dado la gloria que tú me diste, para que sean uno como nosotros somos uno" (Jn 17,22). Esta unión entre Jesús y el Padre es uno de los motivos centrales del evangelio (Jn 1,1; $10,30)$. Esta profunda unión entre ellos se manifiesta en la misión de Jesús, cuyo objetivo no es otro que dar a conocer la vida de Dios y su amor los hombres. Jesús se ha separado del abrazo de amor que le unia con el Padre desde toda la eternidad y ha venido a este mundo para incluir en este mismo abrazo a todos los que crean en él y reconozcan que ha salido del Padre (Jn 16,25-28). El lazo que hace posible duradera esta unión es el amor, del que ahora participan también los discipulos. La unión que Jesús pide para ellos está basada en este 
amor y es participación de la unión que ya existe entre él y el Padre.

En la oración de Jesús se menciona también por dos veces el efecto que producirá esta unión de los discípulos: el mundo podrá creer y reconocer que el Padre ha enviado a Jesús reconocerá también su amor. En el evangelio de Juan «reconocer que el Padre ha enviado Jesús» es una clara manifestación de fe, por tanto lo que se dice aqui es que, gracias al testimonio de la unión entre ellos, y de ellos con Jesús y con el Padre, y gracias a la corriente de amor que pasa por esta unión, muchos otros creerán en Jesús y experimentarán este mismo amor.

Esta parte (vv. 20-23) de la oración de Jesús tiene, por tanto, una intensa orientación misionera. Se dirige a los que han creído gracias al anuncio de los primeros discípulos, y los exhorta para que ellos mismos den un testimonio de fe y de vida que lleve a otros a creer en Jesús. La fe se transmite por el testimonio, y el mejor testimonio, en las comunidades a las que se dirige el evangelista, lo mismo que entre nosotros, es la unidad, no una unidad cualquiera, sino una basada en la unión de amor que se da entre Jesús y el Padre ${ }^{22}$.

\section{Jesús, el Padre y los adversarios}

También en las controversias de Jesús con sus adversarios podemos encontrar rasgos del rostro del Padre. Buen número de ellas no suponen un enfrentamiento abierto, sino sólo desinterés o indiferencia con que algunos oyentes acogieron las palabras de Jesús. Pero otras, en cambio, sí reflejan duras disputas. A propósito de estos últimos casos, conviene decir que en estos textos no sólo subyacen los conflictos de Jesús con las autoridades judias, sino también los altercados posteriores entre éstas y la comunidad cristiana.

Para iniciar este último bloque podemos partir de las reivindicaciones que tanto Jesús como los judíos hacian de Dios como Padre suyo. En esta polémica, Jesús desautoriza imagen que de Dios ofrecían las autoridades de su pueblo; si Dios fuera quien ellos decian, lo acogerían a él y le creerian, pues es su enviado: «Si Dios fuera vuestro Padre, me amaríais mi, porque yo he salido y vengo de Dios; no he venido por mi cuenta, sino que él me ha enviado» (Jn 8,42). Por eso, la enseñanza de Jesús es tan diferente a la de los maestros judíos, pues cada una procede de fuentes distintas, incluso antagónicas: "Yo hablo lo que he visto junto a mi Padre; y vosotros hacéis lo que habéis oído a vuestro padre» (Jn 8,38). Y resultado final es la progresiva enemistad contra Jesús que culminará con su muerte. Pero este rechazo a Jesús es también una repulsa al Padre, al verdadero Dios: «El que me odia, odia también a mi Padre» (Jn 15,23).

$Y$ en estos enfrentamientos se plantea la gran pregunta de los adversarios: "¿Dónde está tu Padre»? Y Jesús responde del mismo modo que a sus discípulos: «No me conocéis ni a mi ni mi Padre; si me conocierais a mí, conocerías también a 
mi Padre» (Jn 8,19). ¿ Y cómo conocer a ambos? Por las obras que juntos realizan: "Ya os lo he dicho, pero no me creéis. Las obras que hago en nombre de mi Padre son las que dan testimonio de mi» (Jn 10,25).

La presencia del Padre se hace visible en las obras de su Hijo. A Dlos, a quien no vemos se le reconoce en las obras realizadas por Jesús y, posteriormente, por sus discípulos. El problema está en discernir bien. Las autoridades judias no supieron ver con los ojos de Dios las obras de Jesús; por lo que no pudieron advertir en ellas al Padre (cfr 10,37-38). Y eso los llevó al hostigamiento y persecución de Jesús: «Jesús les dijo: Muchas obras buenas de parte del Padre os he mostrado. ¿Por cuál de esas obras queréis apedrearme? Le respondieron los judíos: No queremos apedrearte por ninguna obra buena, sino por una blasfemia y porque tú siendo hombre, te haces a ti mismo Dios» (Jn 10,32-33).

Ahora, la identificación de Jesús con su Padre, tan importante para el grupo de los discipulos, se convierte en piedra de tropiezo para sus enemigos, que pueden tolerarle muchas cosas, pero ésta les resulta ya imperdonable (cfr Jn 5,18.43). Para descalificar a Jesús, los jefes del pueblo lo acusaban de estar poseído por algún demonio $(J n$ 8,49). Pero Jesús se mantiene firme en las disputas, hasta el punto de que su vida y su palabra se convierten en juicio para todos los que lo rechazan; juicio del que resultan culpables (cfr 15,22-24).

La presentación que del Padre hace Jesús en estas controversias no difiere de las ya vistas en los apartados anteriores, si bien podemos resaltar el relieve que en estos casos adquiere la decisión de aceptar o no sus obras, que son, a su vez, las del Padre. Ellas revelan al Hijo como enviado del Padre, son las que le acreditan. $Y$ si el Padre se manifiesta en la obras de Jesús, es porque su presencia se da en mayor medida en el testimonio de la personas. Ciertamente, la creación habla de él, pero es sin duda la existencia humana la que mejor remite al Creador. Quien ve a Jesús, al Hijo, ve al Padre. Quien ve a los discípulos, a lo hijos, debe ver también al Padre; aunque en la mayoría de los casos pueda sufrir una decepción, pues asi de limitados y frágiles son los instrumentos que Dios elige para su revelación. Pero es constante en toda la tradición bíblica, ya desde los tiempos más antiguos la predilección de Dios por los testigos más insignificantes. Como así lo demostró también la vida de su Hijo, nacido en el seno de una familia humilde, en un lugar insignificante, muerto del modo más humillante, como un vuigar agitador.

\section{Conclusiones}

La relación entre Jesús y el Padre se expresa en Juan mediante una serie de afirmaciones que ilustran y describen, más o menos profundamente, el misterio de identidad y unidad de una relación única e impensada:

No me conocéis a mí ni a mi Padre: si me conocierais a mi, conoceríais también a mi Padre (Jn 8,19);

Para que todos honren al Hijo como honran al Padre. El que no honra al Hijo no honra Padre que lo ha enviado ( $\mathrm{Jn} 5,23$ );

$\square$ Quien acoja al que yo envíe, me acoge a mí, quien me acoge a mí, acoge a Aquel que me ha enviado (Jn 13,20); 
․ El que cree en mí, no cree en mí, sino en Aquel que me ha enviado; y el que me ve a mi ve a aquel que me ha enviado (Jn 12,44-45);

․ Si me conocéis a mi, conoceréis también a mi Padre (Jn 14,7);

․ El que me ha visto a mi, ha visto al Padre (Jn 14,9);

口. El que me odia a mí, odia también a mi Padre (Jn 15,23).

Todos estos textos señalan diversas actividades humanas que tienen como objeto a Jesús y, por tanto, al Padre. La relación entre Jesús y el Padre está, por tanto, presentada en Juan mediante la imagen del agente plenipotenciario enviado por el Padre. Es uno con el Padre (Jn 10,30; cfr 17,21; 10,38; 14,10.20) y, en este sentido, su función en la tierra será la misma que la de aquel que lo ha enviado. Por eso, quien ha visto a Jesús ha visto al Padre que lo ha enviado (Jn 14,9; cfr 12,45); por lo mismo, quien no honra a Jesús no honra al Padre que lo ha enviado (Jn 5,23).

Ya hemos señalado, que Juan utiliza mucho la palabra «Padre», y lo importante es que fundamentalmente es Jesús quien habla de Dios como Padre, ya que el evangelista sólo se refiera al Padre de Jesús en seis ocasiones (cfr Jn 1,14.18; $5,18 ; 8,27 ; 13,1.3)$, en textos que, bien reproducen títulos ( $\mathrm{Jn} 1,14.18)$, o bien están enlazados con expresiones de Jesús sobre el Padre (Jn 5,18; 8,27), o expresan más de cerca la conciencia de Jesús sobre su misión (Jn 13,1.3). En el fondo, por tanto, estos seis textos quedan plenamente asimilados a la utilización preponderante de Juan: es Jesús quien habla del Padre (76 textos) o de «mi Padre» (25 textos) o se dirige a su Padre (Jn 11,41; 12,27.28; 17,1.5.11.21.24.25: pater en vocativo).

La expresión «el Padre» («mi Padre») sirve a Jesús para expresar quién es aquel que lo ha enviado (25 textos), aquel que está siempre con él (Jn 8,18.29), aquel con quien se siente intimamente identificado ( Jn 10,30). Por eso, como ya hemos constatado, honrar al Hijo es el mismo que honrar al Padre, conocer al Hijo es conocer al Padre, ver al Hijo es ver al Padre, etc. Es interesante notar que, en estos textos, no se dice que quien ve a Jesús puede ver al Padre como diferente de Jesús, como si estuviese «detrás» de Jesús. Este es el sentido que se desprende también de los únicos textos donde otros interlocutores hablan de Dios como Padre: «Entonces le decian: ¿Dónde está tu Padre? Respondió Jesús: no me conocéis ni a mi ni a mi Padre; si me conocierais a mí, conoceríais también a mi Padre» $(\mathrm{Jn} 8,19)$. La realidad de Jesús, una vez conocida, contiene, por así decirlo, el conocimiento del Padre. Por eso, no hemos de dar ningún otro paso, no hemos de conocer a nadie más para conocer al Padre. Basta con conocer a Jesús. En este sentido, un segundo texto negará a los judíos que conozcan a Dios como Padre: «Ellos le dijeron: Nosotros no hemos nacido de la prostitución no tenemos más padre que a Dios. Jesús le respondió: si Dios fuera vuestro Padre, me amariais a mi, porque yo he salido y vengo de Dios...» (Jn 8,41-42).

Es imposible, pues, amar a Dios sin amar a Jesús; por eso les dirá Jesús en el mismo diálogo: "es mi Padre quien me glorifica, de quien vosotros decís: El es vuestro Dios» (Jn 8,54). Finalmente, el último texto es todavía más explícito: "Le dice Felipe: Señor, muéstranos al Padre y nos basta. Le dice Jesús: ¿ Tanto tiempo hace que estoy con vosotros y no me conoces, Felipe? El que me ha visto a mi, ha visto al Padre. ¿Cómo dices tú: Muéstranos al Padre?" (Jn 14,8-10).

El hecho central de la historia de las relaciones de Dios con los hombres es, 
según Juan, que Dios envió a su Hijo para demostrar su prueba de amor, y para que los hombre participaran de la vida divina. Dios es ante todo Padre, porque tiene un Hijo a quien desde toda la eternidad ama y comunica su misma vida divina. El Dios verdadero, el único Dios que existe, es Padre, es el Padre de Jesucristo. El Padre de Jesús quiere ser también el Padre de los hombres que ha creado. No se contenta con amarlos con un amor benevolente que les asegura una breve vida feliz en el marco espléndido de la creación. El Padre de Jesús quiere ser verdadero Padre de los hombres comunicándoles su misma vida eterna, no otra, la misma vida que comunica a su Hijo desde siempre y para siempre, la vida por la que ellos, ya hijos, liegan a ser verdaderos hermanos de ese Hijo.

Después de haber subrayado la relación recíproca que une al Padre y al Hijo, a través de las acciones que realizan juntos, Juan pasa a afirmaciones muy claras y profundas sobre su total unidad. Ellos tienen entre sí un conocimiento que los pone en el mismo orden de pensamiento y de amor ( $\operatorname{cfr} \mathrm{Jn} 10,15$ ), de modo que cada uno esté en comunión con el otro hasta el punto de constituir una sola cosa (cfr Jn 10,30; 17,22), es decir, un solo ser, el ser de uno en el otro (cfr Jn 10,38; 14,10-11,20; 17,21.23).

Todo esto indica de modo muy incisivo la consistencia y la profundidad de la unidad del Hijo con el Padre. La característica particular de la misión de Jesús y su valor salvífico encuentra su fundamento último y su verdadero significado en la relación única y personal de Jesús con el Padre, que lo constituye y lo hace Hijo de Dios.

Para Juan, Dios es fundamentalmente el que dona, el que comunica su voluntad salvifica; y el don más grande que ha hecho a la humanidad es su Hijo, el Unigénito (cfr Jn $1,14.18 ; 3,16.18$ ), para que la humanidad, esclava de las tinieblas, encontrara en él la liberación de toda esclavitud y se volviera partícipe de la misma filiación divina: «A todos los que lo recibieron les dio poder de hacerse hijos de Dios» (Jn 1,12). Este es el don inmenso del Dios Padre, que realiza su obra en la persona de su Hijo, el cual no ha venido a realizar un proyecto personal, sino el encomendado por su Padre. El Padre, en el cuarto evangelio aparece como el centro unificador y totalizador de la existencia del Hijo; su voluntad rige todos los movimientos de su enviado.

Jesús es el "pastor» de sus seguidores, que estarán siempre seguros, porque el Padre no permitirá que ninguno de ellos sea arrebatado de sus manos. Finalmente, si queremos conocer al Padre y descubrir su rostro, tenemos que primeramente conocer a Jesús. 